\title{
Review \\ Neuroprotection in glaucoma: old concepts, new ideas
}

\begin{abstract}
Introduction: The disease process of glaucoma is thought to begin up to twenty years before a diagnosis can be made. While its current treatment paradigm seeks to reduce the rate of disease progression through reducing intraocular pressure, these interventions are of limited effectiveness and are typically made late. Together, this highlights an unmet clinical need for development of novel techniques to facilitate the early diagnosis of glaucoma and the emergence of new treatment paradigms. This review provides a summary of recent developments in the early diagnosis and treatment of glaucoma, including updates on natural neuroprotective compounds.
\end{abstract}

Areas covered: A systematic review of the glaucoma literature was conducted including the keywords retinal ganglion cell apoptosis, neuroprotection, resveratrol, curcumin, adaptive optics, and detection of apoptosing retinal cells (DARC).

Expert commentary: While a growing number of pre-clinical studies have reported efficacy of neuroprotective interventions for the treatment of glaucoma, these technologies have not yet translated into clinical use. A likely explanation for this phenomenon is the relatively late stage at which glaucoma is currently diagnosed in patients. The development of techniques to diagnose glaucoma earlier in the disease process would enable the earlier administration of neuroprotective interventions which could slow glaucoma-associated vision loss.

Keywords: curcumin, DARC, early diagnosis, glaucoma, neuroprotection, resveratrol 


\section{Review \\ Neuroprotection in glaucoma: old concepts, new ideas}

\section{Introduction}

Glaucoma is one of the leading causes of irreversible blindness, affecting more than 60 million people globally (1). Owing to an aging global population, the prevalence of this condition is increasing with over 111 million cases of glaucoma expected by 2040 (2). Glaucoma is a progressive optic neuropathy characterised by excavation ("cupping") of the optic nerve head, leading to progressive visual field loss (3). As described by Casson et al. (4) it is a condition of multifactorial aetiology, diagnosed by observing a "constellation" of clinical features including deformation of the lamina cribrosa associated with axonal compression. Whilst central visual acuity is initially spared, corresponding anatomical and functional nerve-fibre-bundle pattern visual field loss can be detected as the disease progresses.

Glaucoma is subdivided into open-angle and angle-closure, which refers to the iridocorneal angle through which aqueous humour is drained from the eye (3). Both open-angle and angle-closure glaucoma can be further subdivided into primary and secondary subtypes. Primary glaucoma refers to optic nerve head changes in the absence of secondary causes such as inflammation, trauma, neovascularisation or pseudoexfoliation. Primary open-angle glaucoma is subdivided into disease in association with raised intraocular pressure (IOP), or with an apparently normal IOP (normal-tension glaucoma, NTG) (3). The upper limit for "normal" IOP in this instance is defined as greater IOP being in than the 97.5th percentile of the general population $(21 \mathrm{mmHg}$ ) (Figure 1) (4).

It is important to recognise that raised IOP does not always lead to glaucomatous damage (a condition termed ocular hypertension (OHT) (4)), and a subset of glaucoma patients with apparently normal IOP do experience accelerated glaucomatous changes (NTG) (3). This suggests that mechanisms independent of elevated IOP may contribute to the glaucomatous disease process (5). IOP-independent risk factors for glaucoma include age, ethnicity (mainly African) gender (male), a family history, and lower systolic blood pressure (6). Furthermore, some studies suggest that a low CSF pressure may be associated with the development of glaucomatous optic nerve damage. This trend has been observed both in animals and patients with NTG who were found to have higher translaminar cribrosa pressure compared to healthy individuals (7-9).

Retinal ganglion cell (RGC) loss is the pathological hallmark of glaucoma. RGCs convey visual information from the retina to the brain. These are the first type of cells being affected before the activation of microglia (10). The human retina contains 1.5 million RGCs (5) of which $0.4 \%$ are estimated to be lost per year due to the normal ageing process $(11,12)$. Patients with glaucoma are reported to exhibit an accelerated loss of RGCs at an average rate of $4 \%$ per year (13-15). 


\section{Review \\ Neuroprotection in glaucoma: old concepts, new ideas}

While the underlying causes of RGC loss in glaucoma remain to be elucidated, in cases of raised IOP, compression of the axonal nerve fibres and axonal transport impairment are thought to be at least partly responsible for increased rates of RGC apoptosis (16). In the absence of raised IOP, however, additional factors including low ocular blood flow, mitochondrial dysfunction, oxidative stress, inflammation, glutamate excitotoxicity, heat shock proteins and amyloidogenesis are thought to play a role in neurodegenerative processes underpinning the glaucoma disease process $(5,17-20)$.

\section{Diagnosis: Central nervous system plasticity, a double-edged sword}

The diagnosis of glaucoma is presently achieved using a range of techniques that assess existing structural and functional damage in the optic nerve head and retina. Structural information relevant to glaucoma can be gained through slit-lamp examination and imaging of the optic nerve and retina. Accompanying functional assessments are made with perimetry (21). At present, perimetry can only be used to identify a visual field defect when $40-50 \%$ of the RGC population has been lost (22). This delay is due to the ability of the brain and retina to compensate for injury, termed plasticity which can mask considerable retinal damage from diagnostic techniques designed to assess retinal function (23). Although the ability to mask damage has evolutionary advantages and plays a major role in the rehabilitation process post-stroke or trauma (24-26), there is a point beyond which compensatory mechanisms are overwhelmed, continued RGC loss beyond this point is responsible for the rapid and irreversible visual decline associated with glaucoma.

Existing diagnostic techniques for glaucoma appear to share a common flaw whereby their sensitivity to the detection of disease typically increases only as the condition progresses (21). This is problematic as these techniques are less sensitive in the early stages of glaucoma, when therapeutic interventions have the greatest likelihood of modifying clinical outcomes (Figure 2). As current therapies including both existing IOP modulating and emerging neuroprotective therapies are thought to act by reducing the rate of further RGC loss and cannot restore lost function, there is an unmet clinical need for techniques to diagnose glaucoma earlier in the disease process.

\section{Glaucoma therapies to prevent RGC loss: Too little, too late?}

Current therapies for primary open-angle glaucoma aim to slow further disease progression by lowering IOP via topical administration of eye drops (27). The American Academy of Ophthalmology and the European Glaucoma Society recommend reducing IOP by $20 \%$ to $30 \%$ from baseline $(27,28)$ using one 


\section{Review \\ Neuroprotection in glaucoma: old concepts, new ideas}

of five classes of IOP modulating therapies: prostaglandin analogues, beta-blockers, anhydrase carbonic inhibitor, alpha-adrenergic agonists and cholinergic agonists (27). Further evidence for the effectiveness of IOP control for reducing the risk of developing glaucoma is reported by the ocular hypertension study, which found that patients with OHT and without any clinical sign of optic nerve damage (neither on a slit lamp examination nor a visual field assessment) who received IOP lowering therapies, reduced their risk of developing glaucoma by almost $50 \%$ after 5 years of follow-up compared to OHT patients who received no therapies (4.4\% vs $9.5 \%$ respectively) (29).

First line treatment regimens for IOP modulation most commonly comprise prostaglandin monotherapy. Prostaglandin analogues are the most efficient in decreasing the IOP (25 to 35\%) (30) by reducing the resistance outflow to aqueous humour and increasing its uveoscleral passage over a 24 hour period (27). They do not have any reported systemic side effects but can cause ocular irritation, iris darkening and . If prostaglandin analogues are not tolerated, beta-blockers are the next treatment to be started (31)(32). They inhibit production of aqueous humour by the ciliary body resulting in an IOP decrease (32), which is less pronounced than prostaglandin analogues as they do not act during the night (33). Although they are well tolerated and have less ocular side effects, they have life threating contraindications and must not be used in patients with asthma, chronic pulmonary obstructive disease or bradycardia.

If monotherapy with one of the above treatments is not enough to decrease the IOP, another version of the same class is tried (27). Then if it is still not decreasing the IOP properly, it is either replaced or used in combination with a carbonic anhydrase inhibitor or alpha-agonist (32). Earbonic anhydrase inhibitors reduce the aqueous humour production and alpha adrenergic agonists also initially reduce the aqueous humour production but then increase its outflow. Fixed combinations of these drugs are in widespread use including Cosopt (beta blocker with carbonic anhydrase inhibitor), Ganfort (prostaglandin with beta blocker) and Simbrinza (carbonic anhydrase inhibitor with alpha-adrenergic agonist).

While controlling elevated IOP using these therapies can slow the progression of glaucoma, this approach does not work in all cases. Despite having well-controlled IOP, some patients continue to lose vision (34) (Figure 3). For this reason, alternative treatment paradigms to IOP modulation have been sought, providing neuroprotection of RGCs from apoptosis and degeneration. 


\section{Review \\ Neuroprotection in glaucoma: old concepts, new ideas}

\section{Emerging techniques for the early diagnosis of glaucoma}

\section{a. Detection of RGC loss}

As previously discussed, early diagnosis of glaucoma will allow earlier therapeutic intervention with the aim of protecting a higher proportion of RGCs and so preserving patient vision for the greatest time (Figure 2). Prior to the appearance of visual field defects ('pre-perimetric glaucoma') objective monitoring is assisted by OCT imaging which has recently been shown to be predictive of visual field defects (35). However, the detection of significant RNFL thinning typically requires the death of a large number of RGCs (36). In addition, inflammation can cause thickening of the retina which may mask aspects of neurodegenerative decline (37). Another modality, the pattern electroretinogram (PERG) which measures the electrical activity of RGCs can detect their defect earlier (38). A longitudinal study with a follow-up over 10 years showed earlier signs of glaucoma 4 years before its diagnosis by conventional techniques (39). However, it is worth mentioning that PERG was completely normal beforehand and at 4 years it was pathological and saturated making it unsuitable for monitoring the severity of the disease (39). To overcome these limitations, a paradigm shift in glaucoma diagnosis is required whereby instead of attempting to detect deviations from the normal state, we could instead develop techniques for the visualisation of RGC loss process itself. Such an approach is effectively obtained by examining the number of RGCs lost during each year from the graphs presented in Figure 2B. The resulting graphs presented in Figure 3C \& D illustrate that, assuming the rate of RGC loss is constant, such an approach would result in a diagnostic technique that is most sensitive at the earliest stages of the disease process, even if the transition between normal and glaucomatous disease state is not instantaneous.

As RGC loss in glaucoma is thought to occur predominantly through the process of apoptosis, a number of techniques have been developed for the visualisation of apoptotic RGCs in the retina using a confocal scanning laser ophthalmoscope (cSLO) in conjunction with a fluorescently conjugated apoptosis marker. One such technique is DARC (Detection of Apoptosing Retinal Cells). DARC uses fluorescently-labelled annexin $\mathrm{V}$ which selectively binds to cells undergoing apoptosis by binding phosphatidylserine exposed on the plasma membrane of cells in the early stages of apoptosis (40). The visualisation of the fluorescent-labelled annexin V was initially achieved in animal models with cSLO using an argon laser of $488 \mathrm{~nm}$ to excite the fluorophore bound to annexin $\mathrm{V}$, and a photodetector to detect the fluorescent-emitted light (41) with a $521 \mathrm{~nm}$ blocking filter applied (41). DARC has recently completed a first in man clinical trial with a new annexin-bound fluorophore injected intravenously, using an excitation wavelength of $786 \mathrm{~nm}$ and an $800 \mathrm{~nm}$ barrier filter which enables the use of an indocyanine green (ICG) imaging set-up, currently in widespread use to image the choroidal circulation (42). 


\section{Review \\ Neuroprotection in glaucoma: old concepts, new ideas}

DARC has been extensively used as a biomarker in experimental glaucoma models and has been used to assess neurodegeneration and the efficacy of neuroprotective interventions in a number of central nervous system (CNS) disorders (41). Glutamate modulation treatments used in a staurosporine glaucoma model and in a chronic OHT model have been shown to decrease the DARC count (number of apoptosing RGCs seen) (43). DARC was also used to assess the efficacy of amyloid- $\beta$ antibody $(\mathrm{A} \beta \mathrm{ab})$ in the chronic OHT rat model and showed fewer apoptosing RGCs when rats were treated with A $\beta$ ab compared to controls (20). In another glaucoma model, the partial optic nerve transection in rat, the neuroprotective effect of Schwann cell delivery (direct application to injured optic nerve sheath) was shown using DARC (44). DARC has also been used to assess the effect of rosiglitazone in a rotenoneinduced Parkinson's disease model and showed a reduced DARC count in the rosiglitazone-treated group compared to control, suggesting rosiglitazone may be neuroprotective in Parkinson's disease (37). All these promising results using DARC demonstrate its flexible application in assessing the efficacy of neuroprotective treatments.

After these encouraging results on animal models, the DARC phase I clinical trial published in 2017 showed that Annexin $\mathrm{V}$ is safe with good tolerability after intravenous administration (42). The number of apoptosing retinal cells, the so-called DARC count, was found to be significantly increased in patients with glaucoma with the greatest DARC counts correlating with rates of future disease progression assessed using conventional techniques (42). Some of the limitations of this study include the low number of participants per group and the absence of a non-target fluorescent tag to prove that the fluorescent signal is specific. Further analysis of larger numbers of images are required to fully characterise the frequency and distribution of spots in certain diseases versus healthy controls in order to justify the use of DARC as a diagnostic or prognostic tool in humans. There are also improvements to be made in exploring alternative routes of administration thus making the technique quicker to administer and more acceptable to patients. Despite these limitations, these preliminary results are exciting but more clinical studies are needed. Building on this, a phase II clinical trial of DARC is presently in progress studying further glaucoma patients versus healthy controls. Additionally, cohorts of optic neuritis and macular degeneration patients have been included, as well as Down Syndrome subjects (subject to strict ethical scrutiny) who are at increased risk of premature pathological changes of Alzheimer's disease (45).

Alternative methods for the visualisation of apoptotic RGCs include TCapQ, a caspase recognition sequence conjugated to a cell-penetrating TAT-peptide, fluorophore and quencher. TCapQ is ordinarily non-fluorescent but is activated by the presence of cytoplasmic caspase 3 and 7, present in apoptotic cells. $(46,47)$ To date, however, this technology remains in preclinical development. 


\section{Review \\ Neuroprotection in glaucoma: old concepts, new ideas}

\section{b. Towards the label-free visualisation of RGCs}

Owing to their optically transparent nature, RGCs are practically invisible to optical systems.(48) Recent advances in adaptive optics (AO) systems, however, are beginning to bring these elusive cells into focus for the first time under label-free conditions.(49) The first AO system was presented in the 1997 and can now be used with OCT or cSLO to increase the resolution for single cell visualisation. AO is formed of two main parts: a wavefront sensor and a wavefront corrector. The wavefront sensor measures the refractive abnormalities caused by the cornea and the lens. The wavefront corrector, formed by a deformable mirror, corrects these abnormalities resulting in a high-resolution retinal image (50). AOSLO is now able to image single photoreceptors in the central fovea (51), and there is promising clinical evidence to suggest this technique can also be used to image individual RGCs.(49) Although AOSLO is showing promise at visualising cell populations approaching the single cell resolution in a label-free manner, the limited field of view and extensive post-image acquisition processing time presently limits the clinical utility of these technologies.

\section{Neuroprotection - A series of overlapping pathways}

According to the European Glaucoma Society guidelines, the process of neuroprotection describes " $a$ therapeutic approach aiming to directly prevent or significantly hinder neuronal cell damage independently of IOP modulation" (27). To date, a range of neuroprotective therapies for the treatment of glaucoma have been described, predominantly derived from preclinical disease models; but none have yet successfully translated into clinical practice. The remainder of this review will outline recent advances in the development of neuroprotective therapies for the treatment of glaucoma and their potential mechanisms of action.

\section{a. Targeting glutamate excitotoxicity}

Glutamate is the most common neurotransmitter of the CNS (52) and plays a key role in transmitting the action potential from the presynaptic neuron to the postsynaptic neuron through the activation of $\mathrm{N}$ methyl-D-aspartate (NMDA) receptors localised in the synaptic cleft. Implicated in a number of CNS disorders including Glaucoma, (53) Alzheimer's Disease (AD), (54) Traumatic Brain Injury (55) and Stroke (56); excessive extracellular glutamate accumulation is reported to occur as a result of neuronal injury, leading to overstimulation of NMDA receptors. In turn this leads to an increase of intracellular calcium, which stimulates mitochondrial bioenergetics failure through opening of the permeability transition pore, increased production of reactive oxygen species (ROS), cytochrome c release and ultimately apoptosis induction $(57,58)$. 


\section{Review \\ Neuroprotection in glaucoma: old concepts, new ideas}

Memantine is an NMDA-receptor antagonist currently used as a treatment of moderate to late-stage AD and may reduce the rate of dementia progression in some cases $(59,60)$. In a preclinical study where rodents received intravitreal glutamate to mimic excitotoxic environment for three months, intraperitoneal administered memantine showed promise as a neuroprotective agent (61). Despite this early promise, orally administered memantine was later found not to significantly preserve visual function when compared to placebo in a pair of large randomised double-masked placebo-controlled Phase III clinical trials enrolling 2298 patients in total $(62,63)$. The studies were 4 years in length, conducted in parallel 1 year apart, and reported to cost in excess of $\$ 80$ million. Using standard automated perimetry (SAP) and frequency doubling technology (FDT) perimetry as primary endpoints for the first and second studies respectively, no significant benefit of memantine over placebo was found (63).

Several factors in this trial were potentially counter-productive in harnessing any neuroprotective potential of memantine. As a result of the selection criteria, patients were generally in the more advanced stages of disease. Two of the possible inclusion criteria (of which two had to be met if not selected on the basis of a disc haemorrhage in the previous 12 months) were a visual field of $-10 \mathrm{~dB}$ or worse, or cup-to-disc ratio (CDR) of greater than 0.8. This resulted in a mean CDR of $0.8(\mathrm{sd}=0.11)$ amongst the study population. Given that around $28 \%$ of RGCs are thought to be lost when the earliest visual field defects appear (64), it is likely that the cohort of patients in this trial had undergone significant neuronal damage and possible secondary degeneration, a phenomenon suggested to play a role in glaucomatous degeneration $(44,65)$. Furthermore, if we are to believe RGCs continue to function in a state that is less resistant to secondary insults (66), the remaining RGCs may also be less amenable to rescue. As a product of the lack of specific glaucoma biomarkers, exclusion of any patients with concomitant neurodegenerative retinal pathology that may have interfered with visual field tests (i.e. age-related macular degeneration) may have excluded those who stood to benefit most. Similarly for the safety analysis, exclusion of any patients who suffered with previous dizziness (in the past week) could have eliminated those most vulnerable to side effects of memantine.

Secondly, it is questionable as to whether the biomarkers used in the study were sensitive enough to detect meaningful changes in visual function. Indeed, the patients that were confirmed as progressing had to discontinue the drug, preventing retrospective analysis of rates of disease progression whilst taking memantine. As we know from longitudinal visual field studies, rates of disease progression between patients varies significantly (67), with certain disease phenotypes also pooled in the study, such as pseudoexfoliation glaucoma, carrying higher risk of progression (68). The binary outcome of "progressing" or "not progressing" is therefore likely to be over-simplistic. The primary outcomes used 6-monthly visual field testing however, it has been estimated that SAP should be performed in 4monthly intervals for 2 years in order to reliably detect a $-4 \mathrm{~dB}$ change in visual field (69) regardless of 


\section{Review \\ Neuroprotection in glaucoma: old concepts, new ideas}

reliability indices, also not reported in the study results. Most notably, the added sensitivity for early detection of progression from OCT imaging and progression analysis (35) were not available to analyse any neuroprotective effects on rate of disease progression.

Any confounding that may have influenced results is likely to be related to intraocular pressure. It is universally accepted that lowering intraocular pressure reduces rates of glaucomatous progression $(70,71)$. However, in this study several factors were uncontrolled either due to design or presumed ethical reasons. Primarily, the eye drop regimen was left to the discretion of the investigator, without a standardised regimen stated. Not only could IOP and its treatment have varied significantly between groups, but additional neuroprotective benefits may have also been gained by certain patients, as proposed to be the case with brimonidine (72). Secondly, for the post-hoc analyses where a significant difference was found in FDT perimetry progression between $20 \mathrm{mg}$ and placebo in "non-NTG" patients, NTG was not defined but only taken forwards from previous diagnoses, possibly concentrating any confounding effect in this cohort. Thirdly, patients on anti-hypertensives were positively selected via the inclusion criteria as a "high risk" factor, although the nature of this treat was not monitored. However, the interaction between systemic blood pressure, intraocular perfusion pressure and systemic anti-hypertensives is complex $(73,74)$. There is evidence to suggest several anti-hypertensives may affect IOP (75), blunt the efficacy of topical therapies with a similar mode of action to lower it (76), and conversely suggested to lower the requirement for topical therapy in the general population (77).

Moving forwards from this trial, we are hopefully in a better position to study novel neuroprotective agents, whether this is memantine or newer investigative agents. By sophisticating the prospective adaptive trial design and using rate of progression on OCT as a surrogate marker for disease progression, we may have increased sensitivity with which to discover small, as yet undiscovered, but clinically important treatment effects.

In an attempt to resolve one of these potential issues, our group recently reported efficacy of a topical formulation of memantine-loaded PEGylated biodegradable nanoparticles in a preclinical rodent glaucoma model, suggesting this route of delivery may be more effective than oral administration (78).

Patients with AD have an increased rate of glaucoma (25.9\% versus 5.2\% for matched controls) (79). Although this observation is controversial, it is supported by data showing glaucoma patients have more frequently the $\mathrm{AD}$ associated allele epsilon 4 (80)(81) and it has led to the postulation that common mechanisms may underpin glaucoma and other neurodegenerative diseases such as Alzheimer's and Parkinson's disease.(82) One such mechanisms is autophagy dysregulation. Beclin-1 is a protein involved in promoting autophagy, with reduction of beclin-1 impairing autophagy and leading to RGC apoptosis $(83,84)$. Russo et al. reported that high IOP leading to retinal ischemia increased the cleavage 


\section{Review \\ Neuroprotection in glaucoma: old concepts, new ideas}

of beclin-1, a process inhibited by NMDA antagonists (84). These both suggest the importance of autophagy in preventing RGC death, and the potential role of NMDA antagonists such as memantine in the treatment of neurodegenerative diseases.

\section{b. Brimonidine - An IOP-independent modulation effect}

Brimonidine is an alpha-agonist used in glaucoma as an IOP-lowering therapy, however some studies suggest it may also have an IOP-independent neuroprotective effect. In addition to protecting rats with high IOP from axonal degeneration, (85) brimonidine was also protective against oxidative stress in rats by inhibiting the upregulation of NMDA receptors (86). Another preclinical study has shown brimonidine protects RGCs by reducing amyloid- $\beta$ production and stimulating the non-amyloidogenic pathway (87). The neuroprotective efficacy of brimonidine in humans was assessed in the Low-Pressure Glaucoma Treatment Study (LoGTS) published in 2011 (72). It was a randomised, double-masked, multicentre trial comparing the efficacy of brimonidine and timolol in "low-pressure" glaucoma, sometimes interchangeably termed "normal-tension" glaucoma. Enrolled subjects diagnosed with lowpressure glaucoma had an untreated IOP of $\leq 21 \mathrm{mmHg}$, with a glaucomatous visual field defect in at least one eye that corresponded to the appearance of the optic nerve head. 178 subjects were randomised in a $4: 3$ ratio between twice-daily brimonidine $0.2 \%$ and timolol $0.5 \%$ to allow for an expected higher adverse events rate of $20 \%$ in the former, causing greater attrition. The primary outcome measure was visual field progression as detected by pointwise linear regression. The results showed a dramatic difference in the rates of progression, with $39.2 \%$ progressing in the timolol group versus $9.1 \%$ in the brimonidine group $(\mathrm{p}=0.001)$. The IOP-lowering effect was observed to be similar between groups at all timepoints.

This dramatic effect could be interpreted as superiority of brimonidine via IOP-independent neuroprotective mechanisms, similar to those that have been observed with systemic administration in animal models (88-90). However, there are certain characteristics of the trial that must be examined carefully that could invalidate this conclusion. Primarily, there was a significantly higher drop-out rate in the brimonidine group due to drug-related adverse events (28.3\%) compared to the timolol group $(11.4 \%)(\mathrm{p}=0.008)$ which could have masked a subset of patients in the brimonidine group with progressive disease. Whether progressing patients could have been systematically removed from the cohort is an additional possibility, however no association between ocular allergy and progressive disease has been proven, or indeed between the lack of ocular allergy and a neuroprotective effect. The more severe local side-effect profile of brimonidine (e.g. stinging and hyperaemia) compared to timolol may have systematically removed the patients more prone to non-adherence in this treatment cohort. Secondly, the IOP lowering target of $20 \%$ was only seen in $44 \%$ of the brimonidine group and $39 \%$ in the timolol group which may suggest poor compliance with drops. Other hypotheses behind the observed 


\section{Review \\ Neuroprotection in glaucoma: old concepts, new ideas}

effects that might be considered are differences in the effect on diurnal variation, and a possible deleterious effect from timolol on the optic nerve in relation to its local or systemic vasoregulatory effects (91). The neuroprotective effect of brimonidine is therefore still yet to be proven in clinical practice.

\section{c. Coenzyme Q10}

Coenzyme Q10 (CoQ10) is a mitochondrial-targeting antioxidant which is important for the normal function of the electron transport chain. Our group reported that topical CoQ10 protected RGCs in an OHT rodent glaucoma model, when formulated with a vitamin E derivative (92). These findings were supported by a second study which suggested that topical CoQ10 protected RGC apoptosis by reducing extracellular glutamate levels in an IOP-induced transient ischemia rat model (93). Lee et al. reported that CoQ10 diet supplementation in an experimental mouse glaucoma model protected them from RGC loss by both reduction of glutamate excitotoxicity via the blocking of upregulation of NMDA receptors, and reduction of oxidative stress-mediated mitochondrial alteration through preservation of mitochondrial DNA and its expression (94). A clinical study which enrolled 43 open-angle glaucoma patients treated with a monotherapy of $\beta$-blockers showed that CoQ10 and vitamin E topical administration in 22 patients had a beneficial effect on the inner retinal function by improving the pattern electroretinogram compared to 21 patients receiving only the $\beta$-blocker monotherapy (95).

\section{d. Cannabinoids}

Cannabinoids represent another class of molecule which have potential neuroprotective actions via the inhibition of glutamate release, in addition to their ability to decrease IOP (96-98). The inhibition of the fatty acid amine hydrolase which is responsible for cannabinoid degradation, increases RGC survival rate after axotomy in rats compared to controls by activation of the cannabinoid receptor $\left(\mathrm{CB}_{1}\right)(99)$. Likewise, some studies suggest that the inhibition of $\mathrm{CB}_{1}$ or knockout mice for $\mathrm{CB}_{1}$ are more prone to inflammation and excitotoxic stimuli resulting in an increase of neurodegeneration in a multiple sclerosis animal model (100).

\section{e. Neurotrophic factors}

Neurotrophic factors such as brain derived neurotrophic factor (BDNF), nerve growth factor (NGF), ciliary neurotrophic factor (CNTF) and transforming growth factor beta (TGF- $\beta$ ) also play a role in neuroprotection. BDNF is produced by neurons, undergoing both anterograde and retrograde transport and disruption of these transport processes can lead to neuronal apoptosis (101). Intravitreal injection of BDNF in rodent and feline optic nerve injury (crush and transection) models protected RGCs from apoptosis $(102,103)$. In contrast, BDNF treatment alone was found not to be effective in OHT model (104), instead a combination of BDNF with a free radical scavenger (N-tert-butyl-(2-sulfophenyal)- 


\section{Review \\ Neuroprotection in glaucoma: old concepts, new ideas}

nitrone) was required to elicit RGC protection (104). Building on this discovery, combining BDNF with $\mathrm{N}-\omega$-nitro-L-arginine-methylester (L-NAME) was found to amplify the protective effects of BDNF in an optic nerve transection model (105). In this model, L-NAME was found to inhibit nitric oxide synthase (NOS) release which was stimulated by BDNF administration. Further evidences suggesting a deprivation of RGCs in neurotrophic factors were shown by a decrease of RGC apoptosis in animal models of disease which were treated by NGF or CNTF (5). In another model of retinal degeneration induced by intravitreal injection of $A \beta 42$ oligomers, intravitreal injection of TGF- $\beta 1$ was able to decrease the pro-apoptotic factor BAX suggesting a potential neuroprotective role for TGF- $\beta(106,107)$. However, the neuroprotective role of TGF- $\beta$ is controversial in glaucoma as many studies suggest that it increases IOP by stimulating the scarring process in the trabecular meshwork and targeting TGF- $\beta$ pathways might be neuroprotective $(108,109)$.

\section{f. Natural neuroprotective compounds}

Resveratrol is a naturally occurring non-flavonoid polyphenol found in red wine and dark chocolate. First extracted from the Veratrum album L. var grandiflorum in 1939 by Takaoka (110) and its identification in the skin of grapes was achieved in 1976. Plants produce resveratrol in response to stress, fungal infection or UV exposure because it is able to protect the genome from mutations $(111,112)$. It has also been suggested that resveratrol could explain the French paradox, the observation that French people who consume red wine have a lower cardiovascular disease rate despite their high intake of fatty aids.-Resveratrol has antioxidant, anti-inflammatory and anti-apoptotic properties which have been proposed as useful in the treatment of glaucoma. In order to protect against oxidative stress and inflammation, resveratrol scavenges free radicals (113) but also upregulates heme oxygenase-1 (HO-1), a molecule known to protect against glutamate excitotoxicity (114). Resveratrol can also decrease the expression of quinone reductase $2(\mathrm{QR} 2)$ which increases ROS production and might play a role in neurodegenerative diseases (115). Resveratrol directly decreases inflammation by inhibiting cyclooxygenase 1 (COX-1), interleukin-8 (IL-8), prostaglandins and leukotrienes (116), in addition to blocking the release of cytokines and other inflammatory mediators from mast cells, macrophages and neutrophils (116). Microglial cells that release pro-inflammatory molecules such as tumour necrosis factor- $\alpha(\mathrm{TNF}-\alpha)$ and interleukin-1 $\beta$ (IL-1 $\beta$ ) are also inhibited by resveratrol via the activation of sirtuin 1 (SIRT1) pathway (117). Lastly, the anti-apoptotic effect of resveratrol is thought to be due to its inhibitory effect on cytochrome $\mathrm{c}$ and mitochondrial apoptosis-inducing factor (AIF) release along with an increase of the expression of anti-apoptotic gene such as B-cell lymphoma 2 (Bcl-2) (118).

Resveratrol has been assessed in in vitro and in vivo studies using glaucoma models. Coralia et al. reported that trabecular meshwork cells exposed to oxidative stress (40\% oxygen) and co-treated with resveratrol had a decrease of ROS production and inflammatory markers (IL-1 $\alpha$, IL-6, IL-8, and 


\section{Review \\ Neuroprotection in glaucoma: old concepts, new ideas}

endothelial-cell leukocyte adhesion molecule-1 (ELAM-1)), resulting in less apoptosis (119). Rat glaucoma models treated with intraperitoneal resveratrol or in combination with riluzole had less RGC apoptosis (120), with RGC loss reduced more by a combination of these two drugs compared to their individual effect. Importantly, treatment earlier in the disease course in these models showed greater protection against RGC loss (120). Mice with optic nerve crush and treated with a one year diet of resveratrol were also protected from RGC apoptosis, mainly due to a higher expression of cytoplasmic binding immunoglobulin protein $(\mathrm{BiP})$, nuclear $\mathrm{C} / \mathrm{EBP}$ homologous protein $(\mathrm{CHOP})$ and nuclear $\mathrm{X}$ box-binding protein 1 (XBP-1) compared to controls (121). Resveratrol can also modulate IOP as shown by Razali et al. In this study, steroid-induced ocular hypertension mice were treated with resveratrol to decrease eye pressure, mediated by $A_{1}$ adenosine receptor $\left(A_{1} A R\right)(122)$.

Despite in vitro and in vivo studies showing a neuroprotective effect of resveratrol, this effect has not been conclusively demonstrated in clinical trials $(123,124)$. This may be due to its very low bioavailability (125) owing to its hydrophobic nature, that results in low blood concentrations after oral or intravenous administration. Pharmacokinetic studies in vivo have shown that a dose of $0.2 \mathrm{mg}$ injected intravenously results in a plasma concentration of a few nanograms (126). In order to overcome this low concentration, several groups attempted to develop formulations of resveratrol but with limited success regarding its stability and the concentration encapsulated (127). For example, Yang et al. have encapsulated resveratrol up to $6 \mathrm{mg} / \mathrm{mL}$ with a good stability over 3 months but it uses ethanol as cosurfactant (128). Resveratrol has also been formulated in bile acids with a critical micellar concentration of $2 \mathrm{mM}(129)$.

Curcumin (1,7-bis(4-hydroxy-3-methoxyphenyl)-1,6-heptadiene-3,5-dione) is another promising natural polyphenol found in the turmeric plant, Curcuma longa (130). The medicinal properties of Curcuma longa have been known for thousands of years, hence its use in Asian countries as a herbal medicine. This is due to its antioxidant, anti-inflammatory and anti-apoptotic properties (130). The curcumin molecule contributing to these properties was described in 1815. Thanks to these properties, curcumin has potential to treat neurodegenerative diseases such as glaucoma. However, its exceptionally low solubility in water $(11 \mathrm{ng} / \mathrm{mL})(131)$ results in low bioavailability (132) that may contribute to the poor clinical translation of curcumin therapies to the clinic (133).

Curcumin's major effects are due to its antioxidant and anti-inflammatory properties. It can directly scavenge ROS (134) and inhibit NOS (135), but also indirectly upregulate other antioxidant molecules such as superoxide dismutase (SOD) (136) and HO-1 (137) by activating the nuclear factor erythroid 2related factor 2 (Nrf2) (138-140). To decrease inflammatory molecules, curcumin inhibits cyclooxygenase (141) but also upregulates the peroxisome proliferator-activated receptor- $\gamma$ (PPAR- $\gamma$ ) (142) or inhibit transcription factors such as the nuclear factor kappa-light-chain-enhancer of activated 


\section{Review \\ Neuroprotection in glaucoma: old concepts, new ideas}

$B$ cells (NF)-kB which is responsible for the increase of TNF- $\alpha$, a major inflammatory molecule $(134,143)$. Anti-apoptotic effect is elicited by the inhibition of TGF- $\beta$ and caspase-3 (144) along with a down regulation of BAX and an upregulation of BCL-2. In addition, curcumin is also able to inhibit apoptosis induced by Fas and its ligand (FasL) (145) along with necroptosis by inhibiting receptorinteracting protein (RIP) kinases (146).

These effects have been assessed in in vitro and in vivo models of neurodegenerative diseases. Davis et al. reported that curcumin protects against glutamate excitotoxicity in vitro, and that twice daily eye drops can protect from RGC loss in OHT and partial optic nerve transection rat models, observing decreased RGC loss compared to controls (147). In an in vitro study of age-related macular degeneration (AMD), curcumin protected human retinal pigment epithelial cells exposed to hydrogen peroxide $\left(\mathrm{H}_{2} \mathrm{O}_{2}\right)$-induced oxidative stress. Interestingly, curcumin concentration needed to decrease ROS production was 100 times lower than the concentration needed to increase cell viability (134). In another in vitro study, necroptosis induced in primary cortical neurons was inhibited when neurons were treated with curcumin and this effect correlated with an inhibition of RIP kinases (148). In another study, pretreatment of curcumin in the ocular hypertension model was correlated with an increase of BV-2 microglia (149). In another animal model, staurosporine-induced ganglion cell death was decreased by curcumin (150). Additionally, curcumin increased RGC viability in an ischemia/reperfusion model induced by elevating the IOP in rats (151).

Despite these promising effects, few clinical trials using curcumin have been successful. This has led some authors to postulate that continued research into the therapeutic use of curcumin are unlikely to successfully translate to the clinic.(133). As with many of the aforementioned therapies discussed in this review, the low bioavailability of curcumin likely contributes to its poor clinical translation. This has led many researchers to turn to nanotechnology approaches to enhance bioavailability (152). For example, Davis et al. recently reported that curcumin can be solubilised to concentrations of $4.7 \mathrm{mg} / \mathrm{mL}$ using well-characterised excipients with an encapsulation efficiency greater than $95 \%$ and stability over 3 months and efficacy in two preclinical rodent models of glaucoma (147). Diabec ${ }^{\circledR}$, another nanoparticle formulation made of polyvinylpyrrolidone reached the retina with a maximal concentration of $36 \mathrm{pg} / \mathrm{mg}$ at 6 hours after the administration of two capsules (quantity of curcumin not given) in rabbits whereas unconjugated curcumin was not detectable (134). Likewise, Longvida ${ }^{\circledR}$, a solid lipid nanoparticle formulation of curcumin, was found to have an enhanced bioavailability of $22.43 \mathrm{ng} / \mathrm{mL}$ after administration of $650 \mathrm{mg}$ to patients whereas the same quantity of unformulated curcumin administered by the same route was undetectable in the blood (153). Finally, the longest (18 months) double-blind placebo controlled clinical trial of a nanoparticle formulation (Theracurmin ${ }^{\circledR}, 90 \mathrm{mg}$ taken twice a day) showed benefits in patients without dementia (154). Trial endpoints were neuropsychological tests at 6,12 and 18 months $(n=40)$ along with 2-(1-\{6-[(2-[F- 


\section{Review \\ Neuroprotection in glaucoma: old concepts, new ideas}

18]fluoroethyl)(methyl)amino]-2-naphthyl \}ethylidene)malononitrile positron emission tomography (FDDNP-PET) to detect plaques and tangles in vivo $(n=30)$. The trial showed a significant difference between curcumin and placebo group at 18 months regarding the improvement of neuropsychological tests for the curcumin group and FDDNP-PET with a decrease of hypothalamic binding between 0 and 18 months for the curcumin group and an increase of binding in the same region for the placebo group. These promising results might be explained by the use of a nanoparticle formulation to increase the bioavailability (26.2 ng/mL at 18 months) of curcumin but also the enrolment of non-demented patients. As the physiopathologic process of Alzheimer's disease is known to start decades before symptoms (155), targeting the disease before we can diagnose it might limit or delay the disease highlighting the unmet need for diagnostic tools to detect it earlier. However, these results need to be taken cautiously due to the sample size and the ability of curcumin to bind to $\mathrm{A} \beta$ (156) which might interact with the FDDNP-PET (154). Overall these exciting findings suggest a very powerful role of curcumin in the treatment of neurodegenerative conditions but further preclinical studies along with clinical trials are needed.

\section{Conclusions}

For decades neuroprotective compounds have been in research and have shown some efficacy in preclinical studies but none have yet to successfully translated to the clinic for the treatment of glaucoma. While some authors are beginning to postulate that this may be due to an inherent failure in the types of molecules currently under investigation. We postulate that it is the low bioavailability of many of these drug candidates owing to their poor solubility, that may limit clinical efficacy. There is emerging evidence to suggest that nanotechnology based formulation of promising neuroprotective therapies can be used to enhance bioavailability and overcome this problem. Finally, efficacy in many preclinical animal studies involves administration of drugs at early stages of the disease process, something not currently possible in patients. This challenge could be met with the development of new and emerging techniques for the presymptomatic diagnosis of glaucoma.

\section{Expert opinion}

Current glaucoma treatments seek to slow the rate of neurodegeneration by targeting intraocular pressure without addressing the underlying cellular processes involved in RGC loss. In the clinic, we are hindered by our current inability to detect glaucoma at the start of the physiopathologic process when neuroprotective interventions may have the most potential. Further innovative research is therefore 


\section{Review \\ Neuroprotection in glaucoma: old concepts, new ideas}

needed to develop imaging methods in order to detect RGC loss before significant changes to the retinal architecture occur, and the first visual field defects manifest. The ability to diagnose glaucoma earlier will help decrease the burden of this disease if combined with IOP-lowering and neuroprotective treatments.

To date, treatments targeting the underlying disease process remain elusive but the research of new biomarkers and the development of techniques for the presymptomatic diagnosis of glaucoma, coupled with the development of new drug delivery systems and neuroprotective therapies to slow progression of this condition, have the potential to transform glaucoma from a sight threatening condition to one that can be effectively managed with early therapeutic interventions. Novel drug delivery systems have the potential to overcome issues surrounding poor compliance, whilst also improving drug efficacy. Moving forward, new research focusing on neuroprotection and gene therapy will hopefully result in novel treatment approaches translating to clinic in the future. Finally, optic nerve regeneration might become a reality in the next decades, giving new hope to finding a cure for glaucoma.

\section{Key-issues}

- Glaucoma is a progressive optic neuropathy presently diagnosed between ten and twenty years after the start of the disease process

- Treatments for glaucoma are exclusively focused on lowering intraocular pressure, which is not always effective at preserving vision.

- Emerging techniques such as adaptive optic confocal scanning laser ophthalmoscopy or detection of apoptosing retinal cells (DARC) could improve early diagnosis of glaucoma by identifying disease specific patterns of retinal cell loss many years before symptoms present.

- Earlier diagnosis will allow earlier treatment, possibly incorporating the novel treatment paradigm of neuroprotection to complement intraocular pressure modulation.

- Neuroprotective therapies such as resveratrol and curcumin are showing preclinical promise for glaucoma treatment. Research is currently focusing on the use of nanotechnology to formulate these therapies to overcome their limited bioavailability which is impeding clinical translation. 


\section{Review \\ Neuroprotection in glaucoma: old concepts, new ideas}

\section{References}

1. Quigley HA, Broman AT. The number of people with glaucoma worldwide in 2010 and 2020. Br J Ophthalmol. 2006 Mar 1;90(3):262-7.

2. Tham Y-C, Li X, Wong TY, Quigley HA, Aung T, Cheng C-Y. Global Prevalence of Glaucoma and Projections of Glaucoma Burden through 2040. Ophthalmology. 2014 Nov;121(11):2081-90.

3. European Glaucoma Society Terminology and Guidelines for Glaucoma, 4th Edition - Chapter 2: Classification and terminologySupported by the EGS Foundation: Part 1: Foreword; Introduction; Glossary; Chapter 2 Classification and Terminology. Br J Ophthalmol. 2017;101(5):73-127.

4. Casson RJ, Chidlow G, Wood JP, Crowston JG, Goldberg I. Definition of glaucoma: clinical and experimental concepts. Clin Experiment Ophthalmol. 2012 May 1;40(4):341-9.

5. Davis BM, Crawley L, Pahlitzsch M, Javaid F, Cordeiro MF. Glaucoma: the retina and beyond. Acta Neuropathol. 2016 Dec;132(6):807-26.

6. Coleman AL, Miglior S. Risk Factors for Glaucoma Onset and Progression. Surv Ophthalmol. 2008 Nov;53(6):S3-10.

7. Jonas JB, Wang N. Cerebrospinal fluid pressure and glaucoma. J Ophthalmic Vis Res. 2013 Jul;8(3):257-63.

8. Wang N, Jonas JB. Low Cerebrospinal Fluid Pressure in the Pathogenesis of Primary OpenAngle Glaucoma. J Glaucoma. 2013;22:S11-2.

9. Fleischman D, Allingham RR. The role of cerebrospinal fluid pressure in glaucoma and other ophthalmic diseases: A review. Saudi J Ophthalmol Off J Saudi Ophthalmol Soc. 2013 Apr;27(2):97-106.

10. Nickells RW. The cell and molecular biology of glaucoma: mechanisms of retinal ganglion cell death. Invest Ophthalmol Vis Sci. 2012 May 4;53(5):2476-81.

11. Harman. A, Abrahams. B, Moore. S, Hoskins. R. Neuronal density in the human retinal ganglion cell layer from 16-77 years. Anat Rec. 2000;260(2):124-31.

12. Harwerth RS, Wheat JL, Rangaswamy N V. Age-Related Losses of Retinal Ganglion Cells and Axons. Investig Opthalmology Vis Sci. 2008 Oct 1;49(10):4437.

13. Cordeiro MF, Migdal C, Bloom P, Fitzke FW, Moss SE. Imaging apoptosis in the eye. Eye. 2011 May 25;25(5):545-53.

14. Zeyen T. Target pressures in glaucoma. Bull Soc Belge Ophtalmol. 1999;274:61-5.

15. Hirooka K, Izumibata S, Ukegawa K, Nitta E, Tsujikawa A. Estimating the rate of retinal ganglion cell loss to detect glaucoma progression. Medicine (Baltimore). 2016;95(30):e4209.

16. Johnson EC, Deppmeier LM, Wentzien SK, Hsu I, Morrison JC. Chronology of optic nerve head and retinal responses to elevated intraocular pressure. Invest Ophthalmol Vis Sci. 2000 Feb;41(2):431-42.

17. Tan O, Liu G, Liang L, Gao SS, Pechauer AD, Jia Y, et al. En face Doppler total retinal blood flow measurement with $70 \mathrm{kHz}$ spectral optical coherence tomography. J Biomed Opt. 2015 Jun 10;20(6):066004.

18. Osborne NN. Mitochondria: Their role in ganglion cell death and survival in primary open angle glaucoma. Exp Eye Res. 2010 Jun;90(6):750-7.

19. Urbak L, Vorum H. Heat shock proteins in the human eye. Int J Proteomics. 2010;2010:479571.

20. Guo L, Salt TE, Luong V, Wood N, Cheung W, Maass A, et al. Targeting amyloid-beta in glaucoma treatment. Proc Natl Acad Sci. 2007 Aug 14;104(33):13444-9.

21. Mashaghi A, Hong J, Chauhan SK, Dana R. European Glaucoma Society Terminology and Guidelines for Glaucoma, 4th Edition - Part 1Supported by the EGS Foundation. Br J Ophthalmol. 2017 Jan;101(4):1.

22. Kerrigan-Baumrind LA, Quigley HA, Pease ME, Kerrigan DF, Mitchell RS. Number of ganglion cells in glaucoma eyes compared with threshold visual field tests in the same persons. Invest Ophthalmol Vis Sci. 2000 Mar;41(3):741-8.

23. Jones BW, Marc RE, Pfeiffer RL. Retinal Degeneration, Remodeling and Plasticity. 


\section{Review \\ Neuroprotection in glaucoma: old concepts, new ideas}

Webvision: The Organization of the Retina and Visual System. 1995.

24. Sabel BA, Henrich-Noack P, Fedorov A, Gall C. Vision restoration after brain and retina damage: The "residual vision activation theory." In: Progress in brain research. 2011. p. 199262.

25. Dimyan MA, Cohen LG. Neuroplasticity in the context of motor rehabilitation after stroke. Nat Rev Neurol. 2011 Feb;7(2):76-85.

26. Sophie Su Y, Veeravagu A, Grant G. Neuroplasticity after Traumatic Brain Injury. Translational Research in Traumatic Brain Injury. CRC Press/Taylor and Francis Group; 2016.

27. European Glaucoma Society Terminology and Guidelines for Glaucoma, 4th Edition - Chapter 3: Treatment principles and options Supported by the EGS Foundation: Part 1: Foreword; Introduction; Glossary; Chapter 3 Treatment principles and options. Br J Ophthalmol. 2017;101(6):130-95.

28. AAO PPP Glaucoma Panel HC for QEC. Primary Open-Angle Glaucoma PPP - 2015 American Academy of Ophthalmology. 2015.

29. Gordon MO, Beiser JA, Brandt JD, Heuer DK, Higginbotham EJ, Johnson CA, et al. The Ocular Hypertension Treatment Study: baseline factors that predict the onset of primary openangle glaucoma. Arch Ophthalmol (Chicago, Ill 1960). 2002 Jun;120(6):714-20; discussion 829-30.

30. Stewart WC, Konstas AGP, Nelson LA, Kruft B. Meta-analysis of 24-Hour Intraocular Pressure Studies Evaluating the Efficacy of Glaucoma Medicines. Ophthalmology. 2008 Jul;115(7):1117-1122.e1.

31. Stein JD, Ayyagari P, Sloan FA, Lee PP. Rates of Glaucoma Medication Utilization among Persons with Primary Open-angle Glaucoma, 1992 to 2002. Ophthalmology. 2008 Aug;115(8):1315-1319.e1.

32. Lee DA, Higginbotham EJ. Glaucoma and its treatment: a review. Am J Health Syst Pharm. 2005 Apr 1;62(7):691-9.

33. Netland PA, Landry T, Sullivan EK, Andrew R, Silver L, Weiner A, et al. Travoprost compared with latanoprost and timolol in patients with open-angle glaucoma or ocular hypertension. Am J Ophthalmol. 2001 Oct 1;132(4):472-84.

34. Grant WM, Burke JF. Why do some people go blind from glaucoma? Ophthalmology. 1982 Sep;89(9):991-8.

35. Yu M, Lin C, Weinreb RN, Lai G, Chiu V, Leung CK-S. Risk of Visual Field Progression in Glaucoma Patients with Progressive Retinal Nerve Fiber Layer Thinning. Ophthalmology. 2016 Jun;123(6):1201-10.

36. Harwerth RS, Vilupuru AS, Rangaswamy N V., Smith EL. The Relationship between Nerve Fiber Layer and Perimetry Measurements. Investig Opthalmology Vis Sci. 2007 Feb $1 ; 48(2): 763$.

*37. Normando EM, Davis BM, De Groef L, Nizari S, Turner LA, Ravindran N, et al. The retina as an early biomarker of neurodegeneration in a rotenone-induced model of Parkinson's disease: evidence for a neuroprotective effect of rosiglitazone in the eye and brain. Acta Neuropathol Commun. 2016;4.

First study describing an involvement of the retina (RGC loss and RNFL thickening) prior to the brain in an animal model of Parkinson's disease. RGC loss correlates with an increase in DARC count.

38. Pfeiffer N, Tillmon B, Bach M. Predictive value of the pattern electroretinogram in high-risk ocular hypertension. Invest Ophthalmol Vis Sci. 1993 Apr;34(5):1710-5.

39. Bode SFN, Jehle T, Bach M. Pattern Electroretinogram in Glaucoma Suspects: New Findings from a Longitudinal Study. Investig Opthalmology Vis Sci. 2011 Jun 16;52(7):4300.

40. Fadok V a, Voelker DR, Campbell P a, Cohen JJ, Bratton DL, Henson PM. Exposure of phosphatidylserine on the surface of apoptotic lymphocytes triggers specific recognition and removal by macrophages. J Immunol. 1992 Apr;148(7):2207-16.

**41. Cordeiro MF, Guo L, Luong V, Harding G, Wang W, Jones HE, et al. Real-time imaging of single nerve cell apoptosis in retinal neurodegeneration. Proc Natl Acad Sci. 2004 Sep 7;101(36):13352-6.

Proof-of-concept study using DARC in animal models of neurodegenerative diseases. 


\section{Review \\ Neuroprotection in glaucoma: old concepts, new ideas}

**42. Cordeiro MF, Normando EM, Cardoso MJ, Miodragovic S, Jeylani S, Davis BM, et al. Realtime imaging of single neuronal cell apoptosis in patients with glaucoma. Brain A J Neurol.

2017 Jun;140(6):1757-67.

Proof-of-concept study using DARC in humans. Fluorescently-labelled annexin 5 (ANX776) is safe and well-tolerated in humans. DARC count is greater in glaucoma patients than in healthy controls.

43. Guo L, Salt TE, Maass A, Luong V, Moss SE, Fitzke FW, et al. Assessment of Neuroprotective Effects of Glutamate Modulation on Glaucoma-Related Retinal Ganglion Cell Apoptosis In Vivo. Investig Opthalmology Vis Sci. 2006 Feb 1;47(2):626.

44. Guo L, Davis B, Nizari S, Normando EM, Shi H, Galvao J, et al. Direct optic nerve sheath (DONS) application of Schwann cells prolongs retinal ganglion cell survival in vivo. Cell Death Dis. 2014 Oct;5(10):e1460.

45. Head E, Powell D, Gold BT, Schmitt FA. Alzheimer's Disease in Down Syndrome. Eur J Neurodegener Dis. 2012 Dec;1(3):353-64.

46. Qiu X, Johnson JR, Wilson BS, Gammon ST, Piwnica-Worms D, Barnett EM. Single-cell resolution imaging of retinal ganglion cell apoptosis in vivo using a cell-penetrating caspaseactivatable peptide probe. PLoS One. 2014;9(2):e88855.

47. Barnett EM, Zhang X, Maxwell D, Chang Q, Piwnica-Worms D. Single-cell imaging of retinal ganglion cell apoptosis with a cell-penetrating, activatable peptide probe in an in vivo glaucoma model. Proc Natl Acad Sci U S A. 2009 Jun 9;106(23):9391-6.

48. Liang J, Williams DR, Miller DT. Supernormal vision and high-resolution retinal imaging through adaptive optics. J Opt Soc Am A Opt Image Sci Vis. 1997 Nov;14(11):2884-92.

49. Rossi EA, Granger CE, Sharma R, Yang Q, Saito K, Schwarz C, et al. Imaging individual neurons in the retinal ganglion cell layer of the living eye. Proc Natl Acad Sci U S A. 2017 Jan 17;114(3):586-91.

50. Liang J, Grimm B, Goelz S, Bille JF. Objective measurement of wave aberrations of the human eye with the use of a Hartmann-Shack wave-front sensor. J Opt Soc Am A Opt Image Sci Vis. 1994 Jul;11(7):1949-57.

51. Dubra A, Sulai Y, Norris JL, Cooper RF, Dubis AM, Williams DR, et al. Noninvasive imaging of the human rod photoreceptor mosaic using a confocal adaptive optics scanning ophthalmoscope. Biomed Opt Express. 2011 Jul 1;2(7):1864.

52. Watkins JC, Evans RH. Excitatory Amino Acid Transmitters. Annu Rev Pharmacol Toxicol. 1981 Apr;21(1):165-204.

53. Nucci C, Tartaglione R, Rombolà L, Morrone L a., Fazzi E, Bagetta G. Neurochemical evidence to implicate elevated glutamate in the mechanisms of high intraocular pressure (IOP)induced retinal ganglion cell death in rat. Neurotoxicology. 2005;26(5):935-41.

54. Hiruma H, Katakura T, Takahashi S, Ichikawa T, Kawakami T. Glutamate and amyloid betaprotein rapidly inhibit fast axonal transport in cultured rat hippocampal neurons by different mechanisms. J Neurosci. 2003 Oct;23(26):8967-77.

55. Giza CC, Rotenberg A, Medical H, Medical H, Angeles L, Angeles L. Glutamate and GABA imbalance following traumatic brain injury. Curr Neurol Neurosci Rep. 2015;15(5):1-20.

56. Weita T, Zhang S, Tian Y. Progress in Neurobiology Excitotoxicity and stroke : Identifying novel targets for neuroprotection. Prog Neurobiol. 2014;115:157-88.

57. Atlante A, Calissano P, Bobba A, Giannattasio S, Marra E, Passarella S. Glutamate neurotoxicity, oxidative stress and mitochondria. FEBS Lett. 2001 May 18;497(1):1-5.

58. Contreras L, Drago I, Zampese E, Pozzan T. Biochimica et Biophysica Acta Mitochondria : The calcium connection. BBA - Bioenerg. 2010;1797(6-7):607-18.

59. van Marum RJ. Update on the use of memantine in Alzheimer's disease. Neuropsychiatr Dis Treat. 2009;5:237-47.

60. Matsuzono K, Yamashita T, Ohta Y, Hishikawa N, Koike M, Sato K, et al. Clinical Benefits of Memantine Treatment for Alzheimer's Disease in the Okayama Memantine Study II (OMS II). J Alzheimer's Dis. 2015 Jul 24;47(2):487-93.

61. Vorwerk CK, Lipton SA, Zurakowski D, Hyman BT, Sabel BA, Dreyer EB. Chronic low-dose glutamate is toxic to retinal ganglion cells. Toxicity blocked by memantine. Invest Ophthalmol Vis Sci. 1996 Jul;37(8):1618-24. 


\section{Review \\ Neuroprotection in glaucoma: old concepts, new ideas}

62. Nucci C, Martucci A, Giannini C, Morrone LA, Bagetta G, Mancino R. Neuroprotective agents in the management of glaucoma. Eye. 2018 May 23;32(5):938-45.

63. Weinreb RN, Liebmann JM, Cioffi GA, Goldberg I, Brandt JD, Johnson CA, et al. Oral Memantine for the Treatment of Glaucoma. Ophthalmology. 2018 Aug 3;

64. Medeiros FA, Lisboa R, Weinreb RN, Liebmann JM, Girkin C, Zangwill LM. Retinal Ganglion Cell Count Estimates Associated with Early Development of Visual Field Defects in Glaucoma. Ophthalmology. 2013 Apr;120(4):736-44.

65. So K-F, Cui Q, Li H-Y, Ruan Y-W, Ren C-R. Mechanisms of secondary degeneration after partial optic nerve transection. Neural Regen Res. 2014 Mar 15;9(6):565.

66. Osborne NN. Recent clinical findings with memantine should not mean that the idea of neuroprotection in glaucoma is abandoned. Acta Ophthalmol. 2009 Jun;87(4):450-4.

67. Heijl A, Buchholz P, Norrgren G, Bengtsson B. Rates of visual field progression in clinical glaucoma care. Acta Ophthalmol. 2013 Aug;91(5):406-12.

68. Leske MC, Heijl A, Hyman L, Bengtsson B, Dong L, Yang Z, et al. Predictors of Long-term Progression in the Early Manifest Glaucoma Trial. Ophthalmology. 2007 Nov;114(11):196572.

69. Chauhan BC, Garway-Heath DF, Goni FJ, Rossetti L, Bengtsson B, Viswanathan AC, et al. Practical recommendations for measuring rates of visual field change in glaucoma. $\mathrm{Br} \mathrm{J}$ Ophthalmol. 2008 Apr 1;92(4):569-73.

70. Kass MA, Heuer DK, Higginbotham EJ, Johnson CA, Keltner JL, Miller JP, et al. The Ocular Hypertension Treatment Study: a randomized trial determines that topical ocular hypotensive medication delays or prevents the onset of primary open-angle glaucoma. Arch Ophthalmol (Chicago, Ill 1960). 2002 Jun;120(6):701-13; discussion 829-30.

71. Heijl A, Leske MC, Bengtsson B, Hyman L, Bengtsson B, Hussein M, et al. Reduction of intraocular pressure and glaucoma progression: results from the Early Manifest Glaucoma Trial. Arch Ophthalmol (Chicago, Ill 1960). 2002 Oct;120(10):1268-79.

72. Krupin T, Liebmann JM, Greenfield DS, Ritch R, Gardiner S, Low-Pressure Glaucoma Study Group. A Randomized Trial of Brimonidine Versus Timolol in Preserving Visual Function:

Results From the Low-pressure Glaucoma Treatment Study. Am J Ophthalmol. 2011 Apr;151(4):671-81.

73. Leske MC. Ocular perfusion pressure and glaucoma: clinical trial and epidemiologic findings. Curr Opin Ophthalmol. 2009 Mar;20(2):73-8.

74. Cantor E, Méndez F, Rivera C, Castillo A, Martínez-Blanco A. Blood pressure, ocular perfusion pressure and open-angle glaucoma in patients with systemic hypertension. Clin Ophthalmol. 2018 Aug;Volume 12:1511-7.

75. Khawaja AP, Chan MPY, Broadway DC, Garway-Heath DF, Luben R, Yip JLY, et al. Systemic Medication and Intraocular Pressure in a British Population. Ophthalmology. 2014 Aug;121(8):1501-7.

76. Schuman JS. Effects of systemic beta-blocker therapy on the efficacy and safety of topical brimonidine and timolol. Brimonidine Study Groups 1 and 2. Ophthalmology. 2000 Jun;107(6):1171-7.

77. Iskedjian M, Walker JH, Desjardins O, Robin AL, Covert DW, Bergamini MVW, et al. Effect of selected antihypertensives, antidiabetics, statins and diuretics on adjunctive medical treatment of glaucoma: A population based study. Curr Med Res Opin. 2009 Aug 17;25(8):1879-88.

78. Sánchez-López E, Egea MA, Davis BM, Guo L, Espina M, Silva AM, et al. MemantineLoaded PEGylated Biodegradable Nanoparticles for the Treatment of Glaucoma. Small. 2018 Jan;14(2):1701808.

79. Bayer AU, Ferrari F, Erb C. High Occurrence Rate of Glaucoma among Patients with Alzheimer's Disease. Eur Neurol. 2002;47(3):165-8.

80. Wostyn P, Audenaert K, De Deyn PP. Alzheimer's disease and glaucoma: Is there a causal relationship? Br J Ophthalmol. 2009 Dec 1;93(12):1557-9.

81. Cesareo M, Martucci A, Ciuffoletti E, Mancino R, Cerulli A, Sorge RP, et al. Association Between Alzheimer's Disease and Glaucoma: A Study Based on Heidelberg Retinal Tomography and Frequency Doubling Technology Perimetry. Front Neurosci. 2015;9:479. 


\section{Review \\ Neuroprotection in glaucoma: old concepts, new ideas}

82. Bayer AU, Keller ON, Ferrari F, Maag K-P. Association of glaucoma with neurodegenerative diseases with apoptotic cell death: Alzheimer's disease and Parkinson's disease. Am J Ophthalmol. 2002 Jan 1;133(1):135-7.

83. Jaeger PA, Wyss-Coray T. All-you-can-eat: autophagy in neurodegeneration and neuroprotection. Mol Neurodegener. 2009 Apr 6;4(1):16.

84. Russo R, Berliocchi L, Adornetto A, Varano GP, Cavaliere F, Nucci C, et al. Calpain-mediated cleavage of Beclin-1 and autophagy deregulation following retinal ischemic injury in vivo. Cell Death Dis. 2011 Apr 14;2(4):e144-e144.

85. Lambert WS, Ruiz L, Crish SD, Wheeler LA, Calkins DJ. Brimonidine prevents axonal and somatic degeneration of retinal ganglion cell neurons. Mol Neurodegener. 2011 Jan 13;6(1):4.

86. Lee D, Kim K-Y, Noh YH, Chai S, Lindsey JD, Ellisman MH, et al. Brimonidine Blocks Glutamate Excitotoxicity-Induced Oxidative Stress and Preserves Mitochondrial Transcription Factor A in Ischemic Retinal Injury. Barnes S, editor. PLoS One. 2012 Oct 9;7(10):e47098.

87. Nizari S, Guo L, Davis BM, Normando EM, Galvao J, Turner LA, et al. Non-amyloidogenic effects of $\alpha 2$ adrenergic agonists: implications for brimonidine-mediated neuroprotection. Cell Death Dis. 2016;7(12):e2514.

88. Yoles E, Wheeler LA, Schwartz M. Alpha2-adrenoreceptor agonists are neuroprotective in a rat model of optic nerve degeneration. Invest Ophthalmol Vis Sci. 1999 Jan;40(1):65-73.

89. WoldeMussie E, Ruiz G, Wijono M, Wheeler LA. Neuroprotection of retinal ganglion cells by brimonidine in rats with laser-induced chronic ocular hypertension. Invest Ophthalmol Vis Sci. 2001 Nov;42(12):2849-55.

90. Hernández M, Urcola JH, Vecino E. Retinal ganglion cell neuroprotection in a rat model of glaucoma following brimonidine, latanoprost or combined treatments. Exp Eye Res. 2008 May;86(5):798-806.

91. Cordeiro MF, Levin LA. Clinical Evidence for Neuroprotection in Glaucoma. Am J Ophthalmol. 2011 Nov;152(5):715-6.

92. Davis BM, Tian K, Pahlitzsch M, Brenton J, Ravindran N, Butt G, et al. Topical Coenzyme Q10 demonstrates mitochondrial-mediated neuroprotection in a rodent model of ocular hypertension. Mitochondrion. 2017;36:114-23.

93. Nucci C, Tartaglione R, Cerulli A, Mancino R, Spanò A, Cavaliere F, et al. Retinal Damage Caused by High Intraocular Pressure-Induced Transient Ischemia is Prevented by Coenzyme Q10 in Rat. Int Rev Neurobiol. 2007 Jan 1;82:397-406.

94. Lee D, Shim MS, Kim K-Y, Noh YH, Kim H, Kim SY, et al. Coenzyme Q10 Inhibits Glutamate Excitotoxicity and Oxidative Stress-Mediated Mitochondrial Alteration in a Mouse Model of Glaucoma. Investig Opthalmology Vis Sci. 2014 Feb 18;55(2):993.

95. Vincenzo Parisi MCSGDMLRLTMTSTNUMVBF. Effects of Coenzyme Q10 in Conjunction With Vitamin E on Retinal-evoked and Cortical-evoked Responses in Patients With Openangle Glaucoma. J Glaucoma. 2014 Aug 1;23(6):391-404.

96. Chien FY, Wang R-F, Mittag TW, Podos SM. Effect of WIN 55212-2, a cannabinoid receptor agonist, on aqueous humor dynamics in monkeys. Arch Ophthalmol (Chicago, Ill 1960). 2003 Jan;121(1):87-90.

97. Njie YF, Kumar A, Qiao Z, Zhong L, Song Z-H. Noladin Ether Acts on Trabecular Meshwork Cannabinoid (CB1) Receptors to Enhance Aqueous Humor Outflow Facility. Investig Opthalmology Vis Sci. 2006 May 1;47(5):1999.

98. Gobira PH, Vilela LR, Gonçalves BDC, Santos RPM, de Oliveira AC, Vieira LB, et al. Cannabidiol, a Cannabis sativa constituent, inhibits cocaine-induced seizures in mice: Possible role of the mTOR pathway and reduction in glutamate release. Neurotoxicology. $2015 \mathrm{Sep}$ 1;50:116-21.

99. Slusar JE, Cairns EA, Szczesniak A-M, Bradshaw HB, Di Polo A, Kelly MEM. The fatty acid amide hydrolase inhibitor, URB597, promotes retinal ganglion cell neuroprotection in a rat model of optic nerve axotomy. Neuropharmacology. 2013 Sep 1;72:116-25.

100. Pryce G, Ahmed Z, Hankey DJR, Jackson SJ, Croxford JL, Pocock JM, et al. Cannabinoids inhibit neurodegeneration in models of multiple sclerosis. Brain. 2003 Oct 1;126(10):2191202.

101. Pease ME, McKinnon SJ, Quigley HA, Kerrigan-Baumrind LA, Zack DJ. Obstructed axonal 


\section{Review \\ Neuroprotection in glaucoma: old concepts, new ideas}

transport of BDNF and its receptor TrkB in experimental glaucoma. Invest Ophthalmol Vis Sci. 2000 Mar;41(3):764-74.

102. Peinado-Ramón P, Salvador M, Villegas-Pérez MP, Vidal-Sanz M. Effects of axotomy and intraocular administration of NT-4, NT-3, and brain-derived neurotrophic factor on the survival of adult rat retinal ganglion cells. A quantitative in vivo study. Invest Ophthalmol Vis Sci. 1996 Mar;37(4):489-500.

103. Chen $\mathrm{H}$, Weber AJ. BDNF enhances retinal ganglion cell survival in cats with optic nerve damage. Invest Ophthalmol Vis Sci. 2001 Apr;42(5):966-74.

104. Ko ML, Hu DN, Ritch R, Sharma SC. The combined effect of brain-derived neurotrophic factor and a free radical scavenger in experimental glaucoma. Invest Ophthalmol Vis Sci. 2000 Sep;41(10):2967-71.

105. Klöcker N, Cellerino A, Bähr M. Free radical scavenging and inhibition of nitric oxide synthase potentiates the neurotrophic effects of brain-derived neurotrophic factor on axotomized retinal ganglion cells In vivo. J Neurosci. 1998 Feb 1;18(3):1038-46.

106. Fisichella V, Giurdanella G, Platania CBM, Romano GL, Leggio GM, Salomone S, et al. TGF$\beta 1$ prevents rat retinal insult induced by amyloid- $\beta$ (1-42) oligomers. Eur J Pharmacol. 2016 Sep 15;787:72-7.

107. Platania C, Fisichella V, Fidilio A, Geraci F, Lazzara F, Leggio G, et al. Topical Ocular Delivery of TGF- $\beta 1$ to the Back of the Eye: Implications in Age-Related Neurodegenerative Diseases. Int J Mol Sci. 2017 Sep 30;18(10):2076.

108. Prendes MA, Harris A, Wirostko BM, Gerber AL, Siesky B. The role of transforming growth factor $\beta$ in glaucoma and the therapeutic implications. Br J Ophthalmol. 2013 Jun;97(6):680-6.

109. Tellios N, Belrose JC, Tokarewicz AC, Hutnik C, Liu H, Leask A, et al. TGF- $\beta$ induces phosphorylation of phosphatase and tensin homolog: implications for fibrosis of the trabecular meshwork tissue in glaucoma. Sci Rep. 2017 Dec 11;7(1):812.

110. Tomé-Carneiro J, Larrosa M, González-Sarrías A, Tomás-Barberán FA, García-Conesa MT, Espín JC. Resveratrol and clinical trials: the crossroad from in vitro studies to human evidence. Curr Pharm Des. 2013;19(34):6064-93.

111. Schouten A, Wagemakers L, Stefanato FL, van der Kaaij RM, van Kan JAL. Resveratrol acts as a natural profungicide and induces self-intoxication by a specific laccase. Mol Microbiol. 2002 Feb;43(4):883-94.

112. Cantos E, García-Viguera C, de Pascual-Teresa S, Tomás-Barberán FA. Effect of postharvest ultraviolet irradiation on resveratrol and other phenolics of cv. Napoleon table grapes. J Agric Food Chem. 2000 Oct;48(10):4606-12.

113. Leonard SS, Xia C, Jiang B-H, Stinefelt B, Klandorf H, Harris GK, et al. Resveratrol scavenges reactive oxygen species and effects radical-induced cellular responses. Biochem Biophys Res Commun. 2003 Oct 3;309(4):1017-26.

114. Bucolo C, Drago F. Focus on molecules: Heme oxygenase-1. Exp Eye Res. 2009 Dec;89(6):822-3.

115. Oxidative stress and neurodegeneration: The possible contribution of quinone reductase 2. Free Radic Biol Med. 2018 May 20;120:56-61.

116. Alarcón de la Lastra C, Villegas I. Resveratrol as an anti-inflammatory and anti-aging agent: Mechanisms and clinical implications. Mol Nutr Food Res. 2005 May 1;49(5):405-30.

117. Zhang S, Gao L, Liu X, Lu T, Xie C, Jia J. Resveratrol Attenuates Microglial Activation via SIRT1-SOCS1 Pathway. Evid Based Complement Alternat Med. 2017;2017:8791832.

118. Bournival J, Quessy P, Martinoli M-G. Protective Effects of Resveratrol and Quercetin Against MPP+ -Induced Oxidative Stress Act by Modulating Markers of Apoptotic Death in Dopaminergic Neurons. Cell Mol Neurobiol. 2009 Dec 23;29(8):1169-80.

119. Luna C, Li G, Liton PB, Qiu J, Epstein DL, Challa P, et al. Resveratrol prevents the expression of glaucoma markers induced by chronic oxidative stress in trabecular meshwork cells. Food Chem Toxicol An Int J Publ Br Ind Biol Res Assoc. 2009 Jan;47(1):198-204.

120. Pirhan D, Yüksel N, Emre E, Cengiz A, Kürşat Yıldız D. Riluzole- and Resveratrol-Induced Delay of Retinal Ganglion Cell Death in an Experimental Model of Glaucoma. Curr Eye Res. 2015 Feb;1-11.

121. Lindsey JD, Duong-Polk KX, Hammond D, Leung CK, Weinreb RN. Protection of injured 


\section{Review \\ Neuroprotection in glaucoma: old concepts, new ideas}

retinal ganglion cell dendrites and unfolded protein response resolution after long-term dietary resveratrol. Neurobiol Aging. 2015 May;36(5):1969-81.

122. Razali N, Agarwal R, Agarwal P, Kumar S, Tripathy M, Vasudevan S, et al. Role of adenosine receptors in resveratrol-induced intraocular pressure lowering in rats with steroid-induced ocular hypertension. Clin Experiment Ophthalmol. 2015 Feb;43(1):54-66.

123. Turner RS, Thomas RG, Craft S, van Dyck CH, Mintzer J, Reynolds BA, et al. A randomized, double-blind, placebo-controlled trial of resveratrol for Alzheimer disease. Neurology. 2015 Oct 20;85(16):1383-91.

124. Berman AY, Motechin RA, Wiesenfeld MY, Holz MK. The therapeutic potential of resveratrol: a review of clinical trials. NPJ Precis Oncol. 2017;1(1).

125. Walle T. Bioavailability of resveratrol. Ann N Y Acad Sci. 2011 Jan;1215(1):9-15.

126. Walle T, Hsieh F, DeLegge MH, Oatis JE, Walle UK. HIGH ABSORPTION BUT VERY LOW BIOAVAILABILITY OF ORAL RESVERATROL IN HUMANS. Drug Metab Dispos. 2004 Aug 24;32(12):1377-82.

127. Amri A, Chaumeil JC, Sfar S, Charrueau C. Administration of resveratrol: What formulation solutions to bioavailability limitations? J Control Release Off J Control Release Soc. 2012 Mar;158(2):182-93.

128. Li D-C, Zhong X-K, Zeng Z-P, Jiang J-G, Li L, Zhao M-M, et al. Application of targeted drug delivery system in Chinese medicine. J Control Release. 2009 Sep 1;138(2):103-12.

129. Atanacković M, Poša M, Heinle H, Gojković-Bukarica L, Cvejić J. Solubilization of resveratrol in micellar solutions of different bile acids. Colloids Surfaces B Biointerfaces. 2009 Aug 1;72(1):148-54.

130. Ammon H, Wahl M. Pharmacology of Curcuma longa. Planta Med. 1991 Feb 5;57(01):1-7.

131. Kaminaga Y, Nagatsu A, Akiyama T, Sugimoto N, Yamazaki T, Maitani T, et al. Production of unnatural glucosides of curcumin with drastically enhanced water solubility by cell suspension cultures of Catharanthus roseus. FEBS Lett. 2003 Dec 4;555(2):311-6.

132. Gupta SC, Patchva S, Aggarwal BB. Therapeutic Roles of Curcumin: Lessons Learned from Clinical Trials. AAPS J. 2013 Jan 10;15(1):195-218.

133. Nelson KM, Dahlin JL, Bisson J, Graham J, Pauli GF, Walters MA. The Essential Medicinal Chemistry of Curcumin. J Med Chem. 2017 Mar 9;60(5):1620-37.

134. Platania CBM, Fidilio A, Lazzara F, Piazza C, Geraci F, Giurdanella G, et al. Retinal Protection and Distribution of Curcumin in Vitro and in Vivo. Front Pharmacol. 2018 Jun 22;9:670.

135. Dinkova-Kostova AT, Talalay P. Direct and indirect antioxidant properties of inducers of cytoprotective proteins. Mol Nutr Food Res. 2008 Mar 7;52 Suppl 1:S128-38.

136. Panchal HD, Vranizan K, Lee CY, Ho J, Ngai J, Timiras PS. Early Anti-Oxidative and AntiProliferative Curcumin Effects on Neuroglioma Cells Suggest Therapeutic Targets. Neurochem Res. 2008 Sep 26;33(9):1701-10.

137. Jeong G-S, Oh G-S, Pae H-O, Jeong S-O, Kim Y-C, Shin M-K, et al. Comparative effects of curcuminoids on endothelial heme oxygenase-1 expression: ortho-methoxy groups are essential to enhance heme oxygenase activity and protection. Exp Mol Med. 2006 Aug 1;38(4):393-400.

138. Kansanen E, Jyrkkänen H-K, Levonen A-L. Activation of stress signaling pathways by electrophilic oxidized and nitrated lipids. Free Radic Biol Med. 2012 Mar 15;52(6):973-82.

139. Bucolo C, Drago F, Maisto R, Romano GL, D'Agata V, Maugeri G, et al. Curcumin prevents high glucose damage in retinal pigment epithelial cells through ERK1/2-mediated activation of the Nrf2/HO-1 pathway. J Cell Physiol. 2019 Feb 15;

140. Foresti R, Bucolo C, Platania CMB, Drago F, Dubois-Randé J-L, Motterlini R. Nrf2 activators modulate oxidative stress responses and bioenergetic profiles of human retinal epithelial cells cultured in normal or high glucose conditions. Pharmacol Res. 2015 Sep;99:296-307.

141. Lin YG, Kunnumakkara AB, Nair A, Merritt WM, Han LY, Armaiz-Pena GN, et al. Curcumin Inhibits Tumor Growth and Angiogenesis in Ovarian Carcinoma by Targeting the Nuclear Factor- B Pathway. Clin Cancer Res. 2007 Jun 1;13(11):3423-30.

142. Peddada K V., Brown A, Verma V, Nebbioso M. Therapeutic potential of curcumin in major retinal pathologies. Int Ophthalmol. 2019 Mar 5;39(3):725-34.

143. Panahi Y, Hosseini MS, Khalili N, Naimi E, Simental-Mendía LE, Majeed M, et al. Effects of 


\section{Review \\ Neuroprotection in glaucoma: old concepts, new ideas}

curcumin on serum cytokine concentrations in subjects with metabolic syndrome: A post-hoc analysis of a randomized controlled trial. Biomed Pharmacother. 2016 Aug;82:578-82.

144. Awad AS, El-Sharif AA. Curcumin immune-mediated and anti-apoptotic mechanisms protect against renal ischemia/reperfusion and distant organ induced injuries. Int Immunopharmacol. 2011 Aug 1;11(8):992-6.

145. Yu L, Fan Y, Ye G, Li J, Feng X, Lin K, et al. Curcumin Inhibits Apoptosis and Brain Edema Induced by Hypoxia-Hypercapnia Brain Damage in Rat Models. Am J Med Sci. 2015 Jun;349(6):521-5.

146. Wang J, Liu Y, Li X-H, Zeng X-C, Li J, Zhou J, et al. Curcumin protects neuronal cells against status-epilepticus-induced hippocampal damage through induction of autophagy and inhibition of necroptosis. Can J Physiol Pharmacol. 2017 May;95(5):501-9.

*147. Davis BM, Pahlitzsch M, Guo L, Balendra S, Shah P, Ravindran N, et al. Topical Curcumin Nanocarriers are Neuroprotective in Eye Disease. Sci Rep. 2018;8(1):11066.

This study describes a novel nanoparticle formulation of curcumin and shows its efficacy in animal models of glaucoma (OHT and partial optic nerve transection).

148. Dai M, Zhong Z, Sun Y, Sun Q, Wang Y, Yang G, et al. Curcumin protects against iron induced neurotoxicity in primary cortical neurons by attenuating necroptosis. Neurosci Lett. 2013 Mar 1;536:41-6.

149. Yue Y-K, Mo B, Zhao J, Yu Y-J, Liu L, Yue C-L, et al. Neuroprotective Effect of Curcumin Against Oxidative Damage in BV-2 Microglia and High Intraocular Pressure Animal Model. J Ocul Pharmacol Ther. 2014 Oct;30(8):657-64.

150. Burugula B, Ganesh BS, Chintala SK. Curcumin Attenuates Staurosporine-Mediated Death of Retinal Ganglion Cells. Investig Opthalmology Vis Sci. 2011 Jun 16;52(7):4263.

151. Wang L, Li C, Guo H, Kern TS, Huang K, Zheng L. Curcumin inhibits neuronal and vascular degeneration in retina after ischemia and reperfusion injury. PLoS One. 2011;6(8):e23194.

152. Jamwal R. Bioavailable curcumin formulations: A review of pharmacokinetic studies in healthy volunteers. J Integr Med. $2018 \mathrm{Jul}$ 4;

153. Gota VS, Maru GB, Soni TG, Gandhi TR, Kochar N, Agarwal MG. Safety and Pharmacokinetics of a Solid Lipid Curcumin Particle Formulation in Osteosarcoma Patients and Healthy Volunteers. J Agric Food Chem. 2010 Feb 24;58(4):2095-9.

154. Small GW, Siddarth P, Li Z, Miller KJ, Ercoli L, Emerson ND, et al. Memory and Brain Amyloid and Tau Effects of a Bioavailable Form of Curcumin in Non-Demented Adults: A Double-Blind, Placebo-Controlled 18-Month Trial. Am J Geriatr Psychiatry. 2018 Mar;26(3):266-77.

155. Beason-Held LL, Goh JO, An Y, Kraut MA, O’Brien RJ, Ferrucci L, et al. Changes in Brain Function Occur Years before the Onset of Cognitive Impairment. J Neurosci. 2013;33(46):18008.

156. den Haan J, Morrema THJ, Rozemuller AJ, Bouwman FH, Hoozemans JJM. Different curcumin forms selectively bind fibrillar amyloid beta in post mortem Alzheimer's disease brains: Implications for in-vivo diagnostics. Acta Neuropathol Commun. 2018;6(1):75. 


\section{Review}

Neuroprotection in glaucoma: old concepts, new ideas

\section{Figure legends}

Figure 1. Clinical classification of different types of glaucoma with risk factors for each condition. IOP : Intraocular pressure

Figure 2. Use of a deterministic decay function to model effects of early intervention with RGC loss modulating therapies preserves RGC populations. [A] Percentage loss of RGC population in healthy $(0.2 \%$ year), Glaucomatous no therapy (4\%/year, beginning at age 50) and Glaucomatous with treatment (1\%/year) illustrating that earlier commencement of therapy $(55,65$ and 75 years of age respectively) can dramatically improve outcomes. [B] Assuming an RGC population of 1.2 million at age 20, and a constant rate of loss of RGCs derived from Figure 2A, the remaining RGC population under each condition can be determined. [C] The percentage of remaining RGC population at age 100 as a fraction of the expected RGC population of a healthy individual illustrates that earlier commencement of the same therapy dramatically improves the remaining RGC population.

Figure 3. Using a deterministic decay function to illustrate that detecting RGC loss processes is a more effective diagnostic strategy early in the disease process [A] Model of human RGC

population with age in healthy (0.2\% RGC loss/year) and glaucomatous (4\% RGC loss/year, age 50+). Red lines indicate an instant transition from $0.2 \%$ RGC loss/year to 4\% RGC loss per year, Blue lines indicate a slow transition between phases increasing at a rate of $+0.2 \%$ RGC loss/year. [B] Percentage RGC loss at each age [C] Number of RGCs lost per year [D] the average number of RGCs lost during a $24 \mathrm{~h}$ period, assuming dying cells are lost over a $24 \mathrm{~h}$ cycle and the rate of loss is constant with time. 